\title{
Trayectorias universitarias: maestra Teresa de Jesús Cañedo Ortiz (1967-2020)
}

Departamento de Formación y Actualización Académica

Resumen

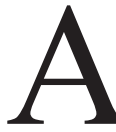
través de este artículo, el Departamento de Formación y Actualización Académica (DEFAA), adscrito a la Dirección General de Docencia de Pregrado de la Universidad Autónoma de Aguascalientes (UAA), presenta una breve semblanza académica de la maestra Teresa de Jesús Cañedo Ortiz, profesora investigadora del Departamento de Educación y Coordinadora de la entonces Unidad de Formación Académica de Profesores (hoy DEFAA) en 2008-2010.

Palabras clave: trayectorias universitarias, docencia, formación docente.

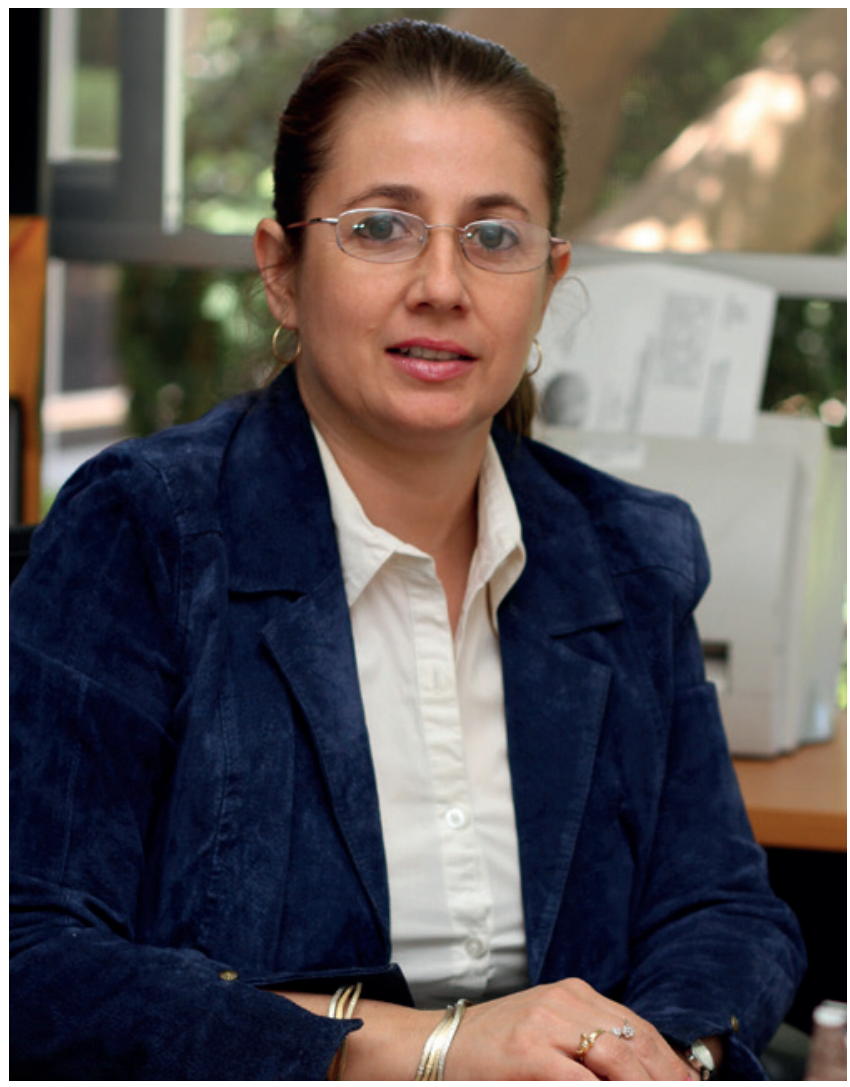

\section{Introducción}

La maestra Teresa de Jesús Cañedo Ortiz estudió la licenciatura en Asesoría Psicopedagógica en la UAA, así como la maestría en Tecnología Educativa en el Instituto Latinoamericano de Comunicación Educativa (ILCE). En 1989 se incorporó como profesora investigadora al Departamento de Educación, del entonces Centro de Artes y Humanidades (hoy Centro de Ciencias Sociales y Humanidades) de la UAA.

Las materias que impartió en licenciatura y posgrado se relacionaron con la tecnología educativa y la metodología de la enseñanza; además, desempeñó diversas actividades vinculadas con el servicio social, como el proyecto "Apoyo psicopedagógico a niños de primaria con problemas en el aprendizaje". Fue coordinadora de servicio social en el Centro de Ciencias Sociales y Humanidades, de 1997 a 2001. Coordinó la maestría en Orientación Educativa (2000-2002), y fue Jefa del Departamento de Educación durante el periodo 2002-2005.

Además, fue directora general del "Centro para el Desarrollo Educacional en Adultos" (CEDEA), bachillerato incorporado al Instituto de Educación de Aguascalientes. 


\section{Formación docente y docencia}

De 2008 a 2010, la maestra Teresa de Jesús Cañedo Ortiz fue Coordinadora de la entonces Unidad de Formación Académica de Profesores (hoy DEFAA). De su gestión, destacan las siguientes acciones:

- Diseño e impartición del Diplomado en Formación de Competencias Básicas para la Docencia, en el marco del proceso de pilotaje del Modelo Curricular por Competencias en tres programas educativos de la UAA.

- Participación en el Programa de Formación Docente de Educación Media Superior (PROFORDEMS), coordinado por la Secretaría de Educación Pública y la Asociación Nacional de Universidades e Instituciones de Educación Superior. En este programa se ofrecieron dos diplomados y un proceso de certificación docente a profesores y directivos de educación media superior a nivel nacional.

- Creación de la revista semestral DOCERE, como un medio para la divulgación de temas relacionados con la docencia en la educación superior y media superior.

Su preocupación sobre la formación docente, se refleja en la siguiente reflexión (Cañedo, 2009, p. 133, en Jiménez y Martínez, 2009):

Reitero mi sentir de que la formación de docentes no es una tarea fácil, es un reto permanente que deberá reflexionarse, cuestionarse y replantearse una y otra vez, quienes en su momento hemos estado al frente de esta gran encomienda seguramente hemos recibido infinidad de críticas y yo no he sido la excepción, sin embargo, considero muy importante escuchar con atención esos comentarios, ya que en el fondo estoy segura, reflejan la preocupación compartida de todos aquellos que formamos esta gran casa de estudios por fomentar un docente de calidad en una mejora continua.
Por otro lado, en el marco del proceso de reestructura organizativa de la Dirección General de Docencia de Pregrado, se creó el Departamento de Innovación Educativa, del cual la maestra Cañedo Ortiz fue su primera jefa de 2011 a 2012.

\section{Conclusiones}

Como se ha podido apreciar, la trayectoria académica de la maestra Teresa de Jesús Cañedo Ortiz refleja una visión sobre la docencia que le permitió participar en diversas iniciativas y acciones para su mejora continua en la Universidad Autónoma de Aguascalientes. Dicha visión puede sintetizarse de la siguiente manera:

Al madurar mi visión educativa, me doy cuenta que la educación en México tiene que mejorar la formación y la actualización docente de manera permanente, considerar [un] cambio en la concepción de nuestros roles como docentes y estudiantes para centrar la enseñanza y el aprendizaje en contenidos significativos, funcionales, básicos y generalizables, atendiendo el desarrollo de competencias centradas en cuatro saberes: ser, hacer, conocer y convivir (Cañedo, 2008, pp. 39-40, en Barba et al., 2008).

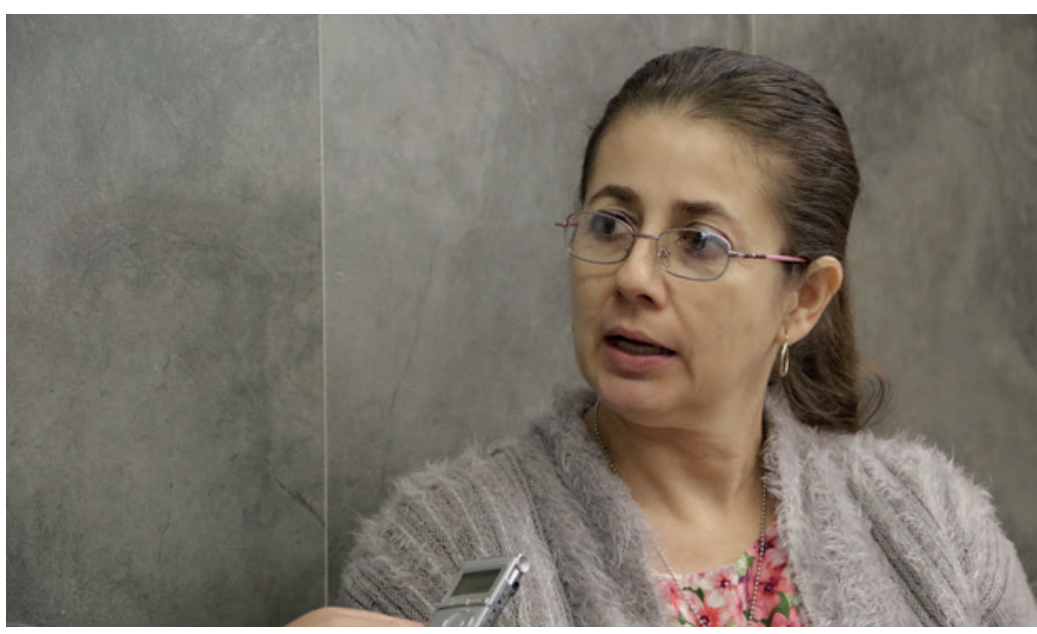

\section{Fuentes de consulta}

Cañedo, T. J. (2008). Planear, pensar y vivir la educación es un gran compromiso. En Barba, J. B. et al. (2008). La experiencia formativa de los educadores: 30 años de trabajo. México: UAA.

Cañedo, T. J. (2009). Testimonio. Ser coordinadora de la UFAP, un gran reto. En Jiménez, M. y Martínez, J. (Coords.). (2009). Testimonios docentes y la formación de profesores en la Universidad Autónoma de Aguascalientes. México: UAA. 